\title{
Clinical and Urodynamic Evaluation in Women with Stress Urinary Incontinence Treated by Periurethral Collagen Injection
}

\author{
S.B. Martins, E. Oliveira, R.A. Castro, M.G. Sartori, E.C. Baracat, G.R. Lima, M.J. Girao \\ Department of Gynecology, Federal University of Sao Paulo, UNIFESP, Sao Paulo, SP, Brazil
}

\begin{abstract}
Objective: To evaluate the success of treatment with periurethral collagen injections in patients suffering from stress urinary incontinence (SUI) with bladder neck hypermobility and intrinsic sphincter deficiency.

Materials and Methods: Forty women suffering from (SUI) were selected and divided into GI (consisting of 13 women with SUI and bladder neck hypermobility) and GII (consisting of 27 women with SUI and intrinsic sphincter deficiency). Periurethral collagen was injected followed by a subjective evaluation (the need for urinary protectors) and an objective evaluation through urodynamic study before and after the treatment.

Results: It was noticed that after 9 months there was a decrease in the need of urinary protectors in the two groups. It was observed through the urodynamic study that either cure or improvement was achieved in $46 \%$ in GI and $40.7 \%$ in GII. There was a significant increase in the leak pressure in GII. Moreover, there was a decrease in the volume of urine leak in the two groups, being the results in GII statistically significant.

Conclusions: It was concluded that the periurethral collagen injection is useful for the treatment of the SUI. The results in hypermobility are similar to those in intrinsic sphincter deficiency. In fact, it is a very simple out patient's procedure, with little side effects.
\end{abstract}

Key words: urinary incontinence, stress; urinary sphincter; injections; collagen

Int Braz J Urol. 2007; 33: 695-703

\section{INTRODUCTION}

In its latest publication, the ICS (International Continence Society) defines the urinary incontinence as the complaint of any involuntary leakage of urine. The stress urinary incontinence (SUI) is the complaint of involuntary leakage on effort or exertion, or on sneezing or coughing. It is the most common type of urinary incontinence (1).

The stress urinary incontinence affects $10 \%$ to $30 \%$ of women above 50 years of age. Patients with intrinsic sphincter deficiency (ISD) present high grade stress urinary incontinence and have low abdominal leak point pressures on urodynamic studies. 
On the other hand, those with bladder neck hypermobility present low grade stress urinary incontinence (2).

Periurethral injection is being used for almost one century for the treatment of stress urinary incontinence. Several substances have been employed, and among them Teflon, autologous fat, silicone microimplants, Durasphere, Zuidex and bovine collagen (24). The injection aims at increasing urethral strength, avoiding thus urinary leak.

Periurethral collagen injection (PCI) has been used in the treatment of SUI due to intrinsic sphincter deficiency since 1993 when it was first approved for this application by the U.S. Food and Drug Administration (5).

It has been reported that stress urinary incontinence associated to intrinsic sphincter deficiency can be treated with reasonable success by means of periurethral collagen injections (6).

However, periurethral collagen injections have also been efficacious in patients with bladder neck hypermobility. The use of collagen in bladder neck hypermobility was evaluated in a nonrandomized prospective study that concluded that this therapy is appropriate in those patients who wish to avoid surgical risks and to whom surgery is ill advised (7).

Because collagen is less invasive than surgery (i.e., retropubic bladder neck suspension or slings), it could represent an interesting alternative for the treatment of SUI. The side effects of collagen injection are generally transient (e.g., urgency, frequency syndrome, retention) $(7,8)$.

Long-term outcomes for the most commercially available bulking agents including collagen demonstrate a cure rate of $25 \%$ to $45 \%$ and an improvement rate of $25 \%$ to $70 \%$. However, due to the decreased effectiveness of collagen with time, repeating injections may be necessary (9).

Most of the studies demonstrate that patient selection is important in the outcomes with PCI. The ideal patient should have diminished urethral function with minimal proximal urethral hypermobility (10).

Thus, in the world literature there is no consensus of opinion that patients with hypermobility will not benefit from PCI.
We evaluated women with SUI with hypermobility and intrinsic sphincter deficiency treated with PCI through clinical criteria (number of urinary protectors) and urodynamic parameters.

\section{MATERIALS AND METHODS}

Between January 2004 and January 200540 women with stress urinary incontinence were studied: 13 with bladder neck hipermobility (GI) and 27 with intrinsic sphincteric deficiency (GII).

All patients underwent a meticulous baseline evaluation, including a complete history, physical examination and urine culture.

They also underwent a urodynamic evaluation that confirmed the diagnosis of stress urinary incontinence in both groups. The urodynamic evaluation was repeated four months after the PCI.

In GII, the ISD was defined as an VLPP of less than $60 \mathrm{~cm} \mathrm{H}_{2} \mathrm{O}$. Bladder neck displacement greater than $10 \mathrm{~mm}$ measured by transperineal ultrasound was used to define bladder neck hipermobility in GI.

The age ranged from 36 to 81 (mean of 60.4). Age was homogeneous between GI and GII. The groups were also homogeneous as to the number of previous surgeries for stress urinary incontinence.

Women who presented contraindications to collagen injections (allergic reaction) were excluded. Subjects with neurogenic bladder, interstitial cystitis and pelvic prolapse higher than stage II were also excluded.

It was agreed that intraurethral collagen submucosal injection under local anesthesia ( 3 to $4 \mathrm{~mL}$ xylocaine $1 \%$ ) as an outpatient procedure would be used for all patients. Collagen was injected at the 3o'clock, and 9-o' clock positions until coaptation of the urethral mucosa was obtained (Figure-1). Sequential injections were given 1 month apart until continence was achieved or until it was predicted that further injections would not provide success. Follow-up visits were conducted at 1, 3, 4, 6 and 9 months after collagen injection.

The success of the intervention was evaluated by means subjective and objective criteria (num- 


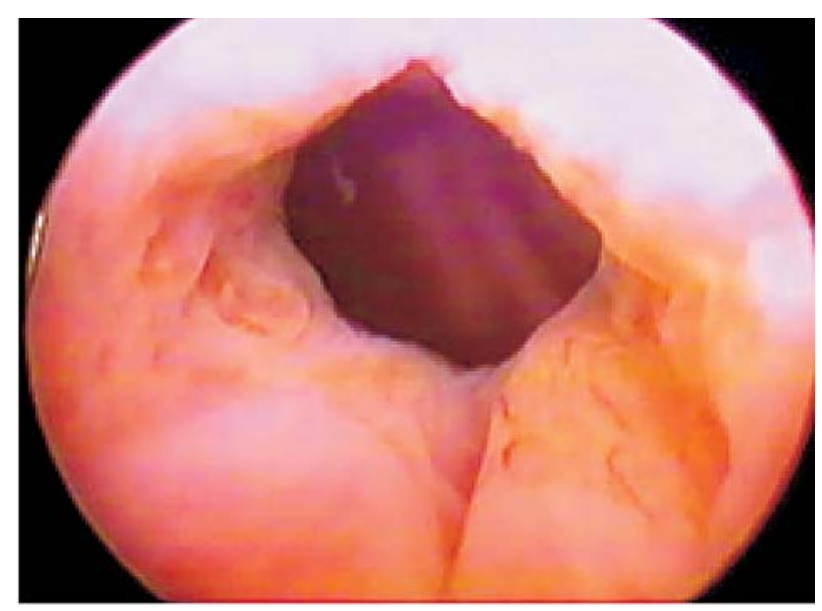

BEFORE

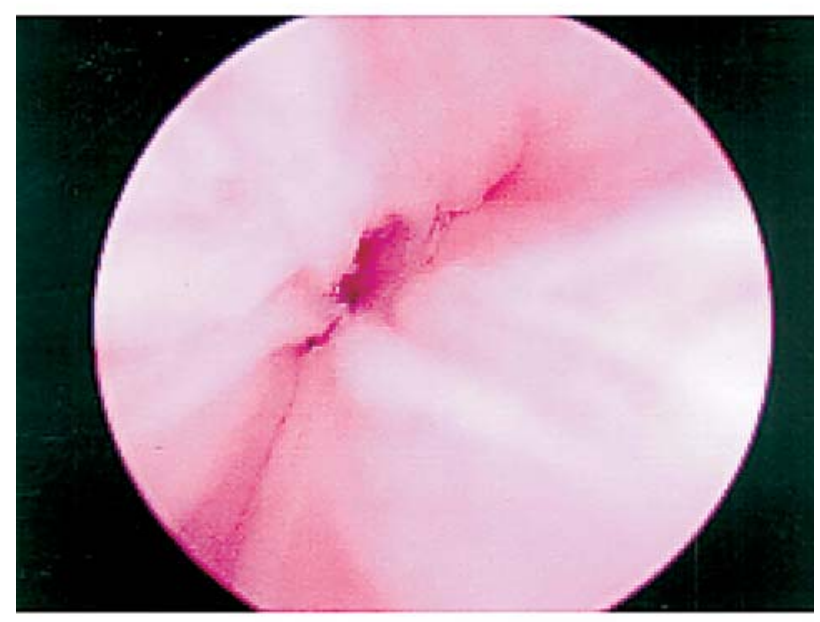

AFTER

Figure 1 - Bladder neck before and after the periurethral injection of collagen.

ber of urinary protectors and urodynamic parameters respectively).

Cure was defined as the absence of urine leak during cistometry performed four months after collagen periurethral injections, improvement when there was urine leak with a volume $50 \%$ bigger than those before treatment and we consider failure when the urine leak occurred with a volume similar to that before PCI.
The study was approved by the Medical Ethics Committee of the Federal University of Sao Paulo, Escola Paulista de Medicina. All patients gave informed consent to participate in the study.

Statistical analysis was performed with the software Analyze-it ${ }^{\circledR}$ for Microsoft ${ }^{\circledR}$ Excel. Statistical significance of differences among the number of urinary protectors, Valsalva leak point pressure, maximum urethral closure pressure and volume of urine leak before and after PCI were assessed using nonparametric tests (Kruskal-Wallis or Mann-Whitney tests, as appropriate). The occurrence of the cure, improvement or failure was assessed using chi-square test. $\mathrm{P}<0.05$ was considered statistically significant.

\section{RESULTS}

The need to use urinary protectors before treatment in GI was smaller than GII. However, after the treatment it was similar in the two groups (Figure2).

It was noticed that after 9 months there was a significant decrease in the need to use urinary protectors in the two groups. (Figure-3).

It was observed through the urodynamic study that either cure or improvement was achieved in $46 \%$ in GI and $40.7 \%$ in GII ( $p>0.05)$ (Table-1).

There was an increase in the leak pressure in both groups, but it was significant only in GII (Graphic2). We also compared the maximum urethral closure pressure (MUCP) in both groups before and after the treatment with periurethral collagen injections and we could not find significant differences (Figure-4).

Besides, there was a decrease in the volume of leakage of urine during urodynamic evaluation in the two groups, being the results in group II statistically significant (Figure-5).

In our series additional injections were given in seven cases of GI and fifteen of GII ( $p>0.05)$. As for the volume of injection, there were no differences between GI and GII.

As far as side effects are concerned, there was no case of urinary retention. There was a case of urinary infection in GI and another in GII, both were successfully treated. 


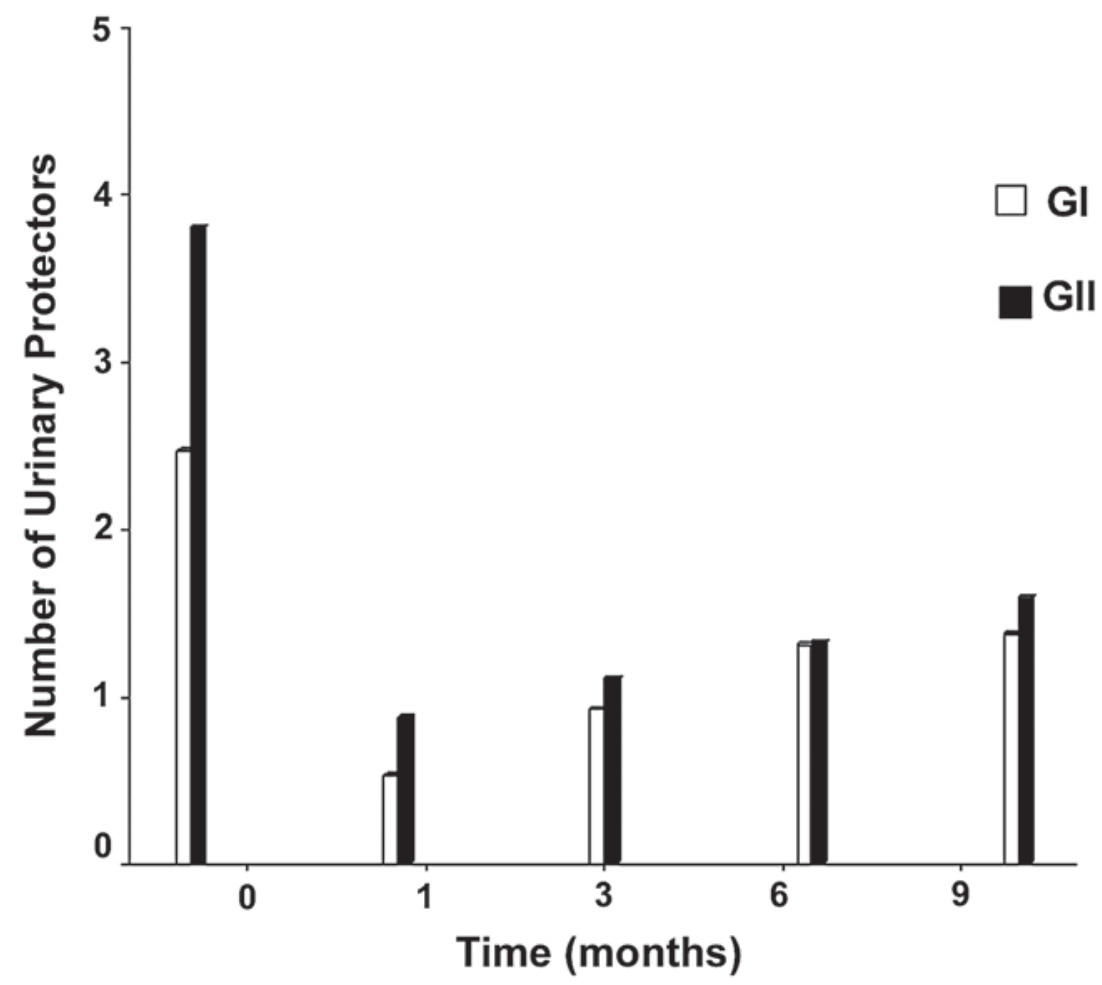

Figure 2 - Number of urinary protectors before and after periurethral injections. Before (GIX GII): Kruskal-Wallis test ( $p<0,05) \therefore$ GII > GI. After - 1, 3, 6 and 9 months: (GI X GII): Kruskal-Wallis test ( $p>0.05) ; 1,3,6$ and 9 months: (GI X GI): Kruskal-Wallis test ( $p<$ 0.05); 1, 3, 6 and 9 months: (GII X GII): Kruskal-Wallis test ( $p<0.05)$.

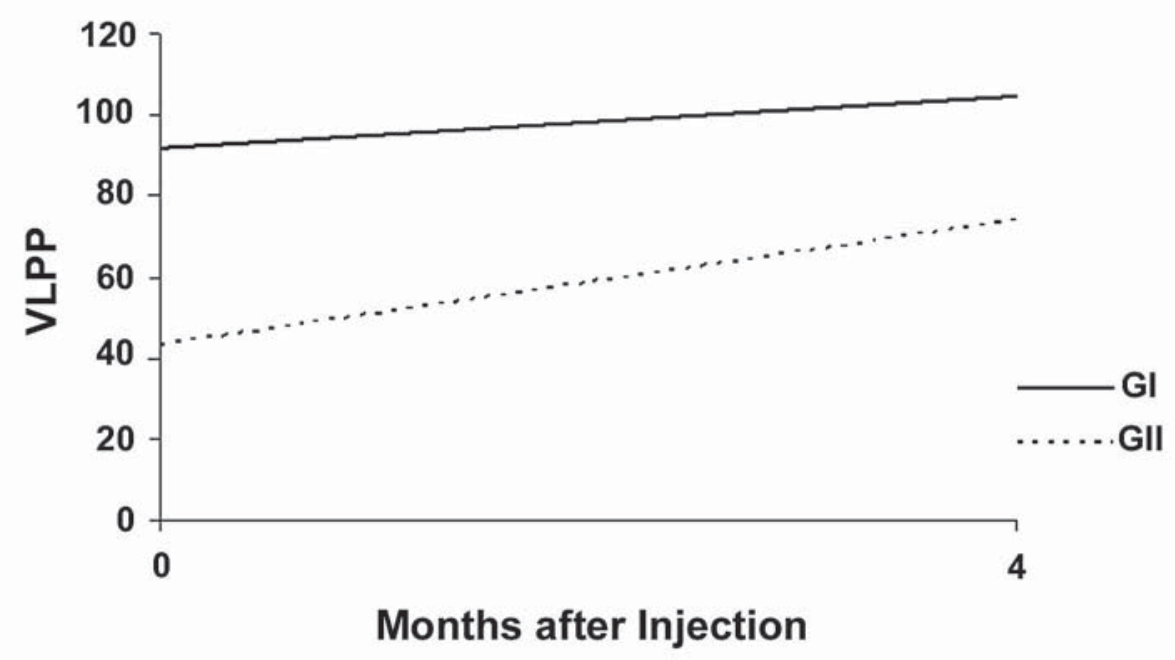

Figure 3 - Behavior of Valsalva leak point pressure before and after treatment with periurethral injection.GI: Kruskal-Wallis test: $p$ > 0.05, GII: Kruskal-Wallis test: $p<0.05$. 
Table 1 - Cystometric evaluation in the different groups.

\begin{tabular}{lcccc}
\hline Groups & Cure & $\begin{array}{c}\text { Outcome } \\
\text { Improvement }\end{array}$ & Failure & Total \\
\hline GI & 3 & 3 & 7 & 13 \\
& $(23 \%)$ & $(23 \%)$ & $(54 \%)$ & \\
GII & 3 & 8 & 16 & 27 \\
& $(11.1 \%)$ & $(29.6 \%)$ & $(59.3 \%)$ & 40 \\
\hline
\end{tabular}

$\chi^{2}$ statistic $=1.0 ; p=0.6007$.

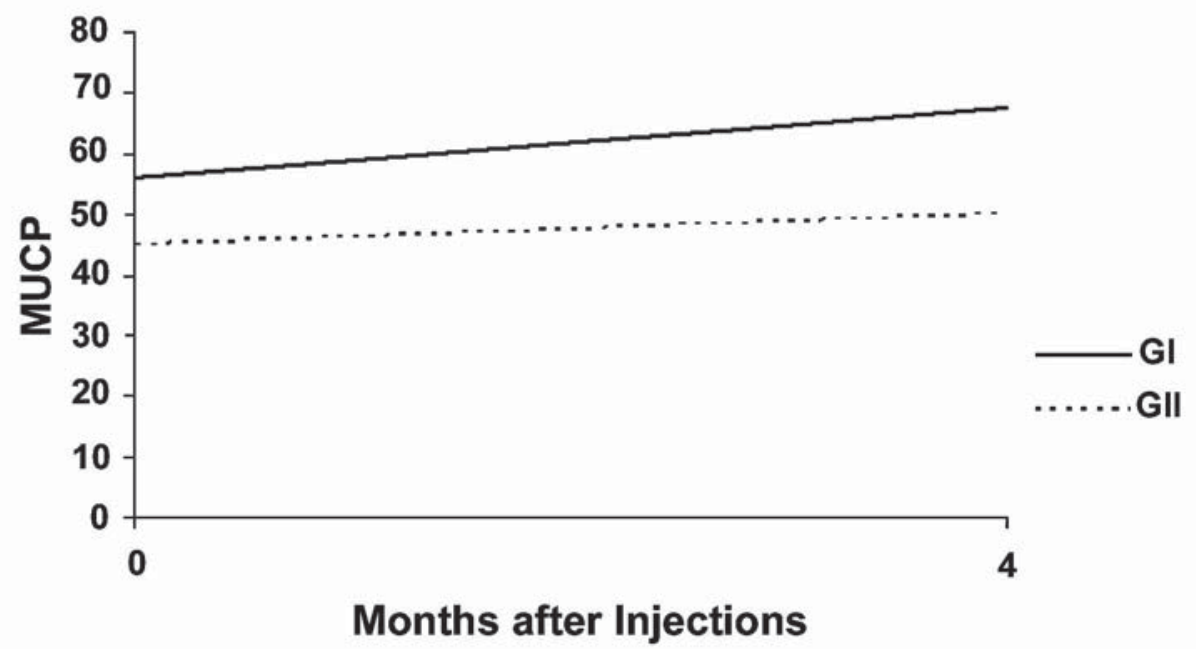

Figure 4-Behavior of maximum urethral closure pressure (MUCP) before and after treatment with periurethral injection.GI: KruskalWallis test: $p>0.05$, GII: Kruskal-Wallis test: $p>0.05$

\section{COMMENTS}

Collagen is a popular, safe and effective periurethral bulking agent for the treatment of stress urinary incontinence primarily due to intrinsic sphincter deficiency.
The procedure may be done under local anesthesia, the period of convalescence is short, and complications are minimal (11).

The reported success rate of collagen injection varies considerably according to patient selection and follow-up duration and also according to the in- 


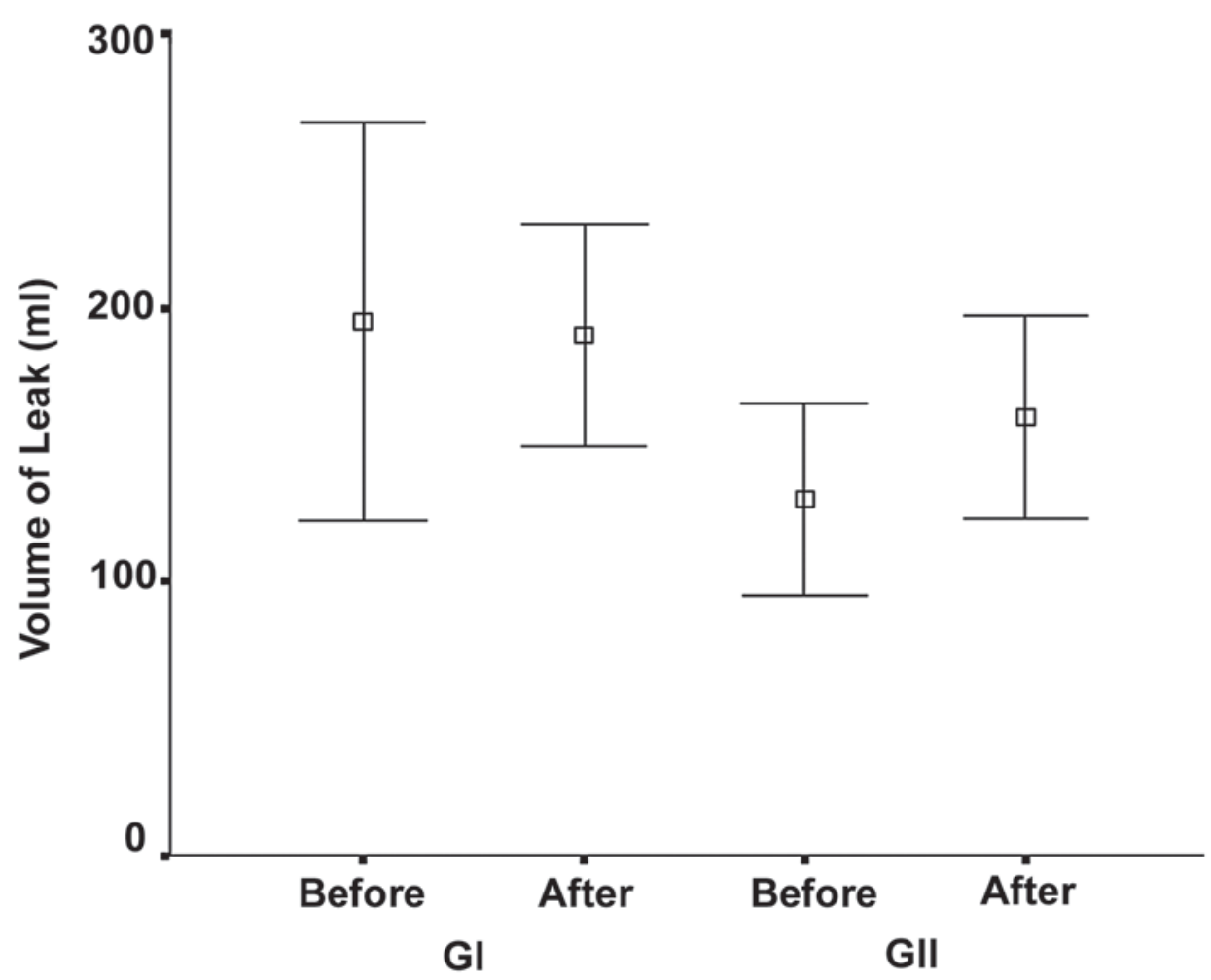

Figure 5 - Volume of leakage before and after treatment with periurethral injections. GI (Before X After): Anova - p > 0.05, GII (Before $X$ After): Anova $-p<0.05$.

Descriptive Statistics:

\begin{tabular}{lllcccc}
\hline & & N & Minimum & Maximum & Mean & SD \\
\hline \multirow{2}{*}{ GI } & Before & 13 & 100,00 & 400,00 & 188,4615 & 91,6375 \\
& After & 10 & 100,00 & 300,00 & 190,0000 & 56,7646 \\
\multirow{2}{*}{ GII } & Before & 27 & 100,00 & 200,00 & 129,6296 & 46,5322 \\
& After & 24 & 100,00 & 200,00 & 162,5000 & 49,4535 \\
\hline
\end{tabular}

vestigator definition of cure, improvement and failure.

There has been a previous collagen outcome assessed by direct patient questioning on symptom severity and pad requirements $(12,13)$. The outcome reported cure in $23 \%$ to $74 \%$ of cases, improvement in $20 \%$ to $52 \%$ and failure in $6 \%$ to $33 \%$.

Our results are similar from those concerning the cure and improvement rates in the world literature. However, we believe that most cases reported as cured in previous studies would be reclassified as improved by our strict criteria. Moreover, cure should imply the reestablishment of normal voiding patterns but in most studies cure denotes that the patient no longer had stress urinary incontinence. Thus, in most cases our new onset urge incontinence, urinary urgency or difficult voiding may have been present.

As opposed to these favorable long-term results, collagen injection is not considered to be a durable procedure and most patients need additional treatment sessions to achieve and maintain improvement or cure. In our series in seven cases additional injections were given in GI and fifteen in GII ( $p>0.05)$. In 
addition, there have not been differences of injection volume between the two groups.

Our study observed a graduated increase of the need of urinary protectors through consecutive months after PCI (Graphic-1). This can be an evidence of the low durability of this procedure.

We also observed urodynamic parameters that have denoted that PCI can be useful in SUI with intrinsic sphincter deficiency. In this group there was a significant increase of the VLPP (Graphic-2). This finding was also reported by other authors $(14,15)$. Overall the literature is inconclusive on the association of improved incontinence grade and increased leak point pressure after treatment as well as the predictive nature of baseline leak point pressure (7).

Among some of the issues addressed in this paper there are the value of collagen injections in patients with hypermobility and ISD. Regarding hypermobility, ISD became the sole indication for the use of collagen in patients with stress urinary incontinence as a result of the US multicentric trial (16). Since then a number of reports have demonstrated the use of collagen in patients with hypermobility. Herschorn \& Radomski (17) found no difference in outcomes with stress urinary incontinence with hipermobility and ISD. The series of Moore et al. (18) included patients with both types of SUI.

In the editorial by McGuire \& Appell (6), the results at more than 1 year in women with ISD were statistically similar to those in women with hypermobility, although Appell (19) subsequently reported that the all patients with hypermobility required bladder neck surgery with 2 years.

In our study, we found similar decrease in the need to use urinary protectors in both groups. Moreover, cystometric evaluation allowed us to infer that outcome results for hypermobility or ISD are similar.

Therefore, in the light of these several recent studies, including our own, we concur that urethral hypermobility is not a contraindication to injection therapy.

\section{CONCLUSIONS}

In our series either cure or improvement was achieved in $46 \%$ of the patients in GI and $40.7 \%$ in
GII. Therefore, periurethral collagen injection may provide a minimally invasive means to treat both types of stress urinary incontinence. We concur that bladder neck hypermobility is not a contraindication to injection therapy.

\section{CONFLICT OF INTEREST}

None declared.

\section{REFERENCES}

1. Abrams P, Cardozo L, Fall M, Griffiths D, Rosier P, Ulmsten U, et al.: The standardisation of terminology in lower urinary tract function: report from the standardisation sub-committee of the International Continence Society. Urology. 2003; 61: 37-49.

2. Appell RA: Valsalva leak point pressure (LPP) vs. urethral closing pressure profile (UPP) in the evaluation of intrinsic sphincter deficiency (ISD). Presented at annual meeting of American Urogynecology Society, Toronto, Ontario, Canada, September. 1994; pp 21-4.

3. Lightner D, Calvosa C, Andersen R, Klimberg I, Brito CG, Snyder J, et al.: A new injectable bulking agent for treatment of stress urinary incontinence: results of a multicenter, randomized, controlled, double-blind study of Durasphere. Urology. 2001; 58: 12-5.

4. Chapple CR, Haab F, Cervigni M, Dannecker C, FianuJonasson A, Sultan AH: An open, multicentre study of NASHA/Dx Gel (Zuidex) for the treatment of stress urinary incontinence. Eur Urol. 2005; 48: 488-94.

5. Kershen RT, Dmochowski RR, Appell RA: Beyond collagen: injectable therapies for the treatment of female stress urinary incontinence in the new millennium. Urol Clin North Am. 2002; 29: 559-74.

6. McGuire EJ, Appell RA: Transurethral collagen injection for urinary incontinence. Urology. 1994; 43: 413-5.

7. Bent AE, Foote J, Siegel S, Faerber G, Chao R, Gormley EA: Collagen implant for treating stress urinary incontinence in women with urethral hypermobility. J Urol. 2001; 166: 1354-7.

8. Corcos J, Collet JP, Shapiro S, Herschorn S, Radomski SB, Schick E, et al.: Multicenter randomized clinical trial comparing surgery and collagen injections for treatment of female stress urinary incontinence. Urology. 2005; 65: 898-904. 
9. Shortliffe LM, Freiha FS, Kessler R, Stamey TA, Constantinou CE: Treatment of urinary incontinence by the periurethral implantation of glutaraldehyde cross-linked collagen. J Urol. 1989; 141: 538-41.

10. Dmochowski RR, Appell RA: Injectable agents in the treatment of stress urinary incontinence in women: where are we now? Urology. 2000; 56: 32-40.

11. Appell RA: Collagen injection therapy for urinary incontinence. Urol Clin North Am. 1994; 21: 177-82.

12. Winters JC, Chiverton A, Scarpero HM, Prats LJ Jr: Collagen injection therapy in elderly women: long-term results and patient satisfaction. Urology. 2000; 55: 856-61.

13. Cross CA, English SF, Cespedes RD, McGuire EJ: A followup on transurethral collagen injection therapy for urinary incontinence. J Urol. 1998; 159: 106-8.

14. Smith DN, Appell RA, Winters JC, Rackley RR: Collagen injection therapy for female intrinsic sphincteric deficiency. J Urol. 1997; 157: 1275-8.
15. Herschorn S, Radomski SB, Steele DJ: Early experience with intraurethral collagen injections for urinary incontinence. J Urol. 1992; 148: 1797-800.

16. Elsergany R, Elgamasy AN, Ghoniem GM: Transurethral collagen injection for female stress incontinence. Int Urogynecol J Pelvic Floor Dysfunct. 1998; 9: 13-8.

17. Herschorn S, Radomski SB: Collagen injections for genuine stress urinary incontinence: patient selection and durability. Int Urogynecol J Pelvic Floor Dysfunct. 1997; 8: 18-24.

18. Moore KN, Chetner MP, Metcalfe JB, Griffiths DJ: Periurethral implantation of glutaraldehyde cross-linked collagen (Contigen) in women with type I or III stress incontinence: quantitative outcome measures. Br J Urol. 1995; 75: 359-63.

19. Appell RA: Periurethral injection therapy. In: Walsh PC, RetikAB, Vaughan ED, et al.: (ed.), Campbell's Urology, 7th ed. Philadelphia, WB Saunders. 1998, pp. 1109-20.

Accepted after revision: April 25, 2007
Correspondence address:

Dr. Sérgio Brasileiro Martins

Rua Hélio Pelegrino, 250 Ap. 112

São Paulo, SP, 04513-100, Brazil

E-mail: emerson_oliveira@terra.com.br

\section{EDITORIAL COMMENT}

The authors present their results of periurethral collagen injections in 27 women with stress urinary incontinence.

Most studies to date have some urodynamic outcomes included. Most are also of longer duration. It is not clear from the introduction just what question the authors want to address.

It is also not mentioned whether patients were given additional injections. It is well known that injectables, especially collagen, may require a few initial sessions for success. If this was not done, it may have compromised the continence outcome.

Regarding the treatment outcomes, the demonstrated leak on cystometry is understood, but there are many patients who do not leak with catheters in place. Do they possibly mean a cough-stress test as an outcome measure? Furthermore, what do they mean by volume of leakage? Is it volume in the blad- 
der at which the leakage occurred? If so, then they should provide evidence that this test has been validated and standardized as an outcome measure.

It appears that the results of treatment in both groups are similar, despite the pre-treatment testing, and despite some discrepancies in urodynamic results.

In the Comments, the authors point to discrepancies between their results and previously published outcomes. From the data they present, the success rates appear relatively similar. Longer term re-

\section{EDITORIAL COMMENT}

This looks at 40 women suffering from stress urinary incontinence over a one-year period. It is not clear on what basis patients were differentiated into the group with intrinsic sphincter deficiency and those with normal sphincters - it is a very vague area and it is difficult to separate out the groups. Clearly though sults are mostly less favorable than short-term results. Furthermore, there are clinical outcome measures that are valid in SUI studies. This study has no clinical outcome measures, e.g. validated questionnaires, against which to compare the urodynamic results.

The authors indicate the lack of durability as evidenced by the increasing need for pads. They then state that collagen can be useful in SUI with ISD. However, they actually showed that the results in patients with normal sphincters (GII?) were the same.

Dr. Sender Herschorn

Sunnybrook and Women's College

Health Sciences Center

Toronto, Ontario, Canada

E-mail:s.herschorn@utoronto.ca

it is a consecutive series followed up prospectively the authors do not mention Zuidex, which is a new agent, which has been around for some time now, and this is an oversight in their literature survey.

Under results, it is interesting to see that there is limited cure shown urodynamically.

Dr. Christopher R. Chapple Department of Urology Royal Hallashire Hospital Sheffield, United Kingdom E-mail: c.r.chapple@shef.ac.uk 